\title{
Chemical and rheological aspects of gel formation in the California Mastitis Test
}

\author{
David Whyte ${ }^{*}$, Michael Walmsley ${ }^{2}$, Alvin Liew ${ }^{2}$, Rod Claycomb ${ }^{1}$ and Graeme Mein ${ }^{1}$ \\ ${ }^{1}$ Sensortec Ltd, PO Box 11004, Hamilton, New Zealand \\ ${ }^{2}$ Department of Materials Science, The University of Waikato, Private Bag 3105, Hamilton, New Zealand
}

Received 27 April 2004 and accepted for publication 5 July 2004

\begin{abstract}
The rheological properties of the CMT gel were analysed. Data are presented to demonstrate that the gel is a non-homogenous, visco-elastic, non-Newtonian fluid with rheopectic, and rheodestructive behaviour. The fundamental chemistry of the CMT is reviewed and a modified theory of gel formation is presented. The implications of the rheological properties and modified theory of gel formation for an automatic sensor are discussed.
\end{abstract}

Keywords: Mastitis, SCC, sensor, milk.

Measurement of the somatic cell count (SCC) in raw milk is widely accepted as an indicator of mastitis and milk quality. Most milk processors test the composite SCC of their suppliers' milk tanks on a regular basis. In many countries, farmers' milk payment is then related to the SCC of their daily or weekly bulk milk supply. Additionally, herd recording agencies usually measure SCC of individual cows on a periodic basis. Measurement techniques employed by the milk processors and the herd recording agencies typically use accurate but expensive laboratory test equipment, such as the use of a toxic cell-staining reagent for automated florescence measurement (Fossomatic, Foss Electric, DK-3400 Hillerød, Denmark). To achieve a faster, but less accurate result, some farmers use a simple, inexpensive, cow-side test, known as the California Mastitis Test (CMT), to provide a qualitative estimate of SCC in the foremilk of individual cows or quarters. CMT, also known as the Rapid Mastitis Test, Schalm test or Mastitis N-K test was developed nearly 50 years ago by Schalm \& Noorlander (1957) who modified the Whiteside test (Whiteside, 1939). The test involves the addition of an anionic reagent to the milk. The reagent interacts with mastitic milk to form a gel. The chemical and rheological nature of the gel has not been studied extensively. It is known that the viscosity of the gel is proportional to the DNA content of the milk (Milne \& DeLangen, 1977) and that DNase (Singh \& Marshall, 1966) and proteinases (Dounce \& Monty, 1955) stop the gel from forming.

Mastitis causes significant economic losses to dairy farmers. Although the exact cost is difficult to quantify,

*For correspondence; e-mail: dw@sensortec.co.nz estimates are US\$1.5-2 billion/year in the USA (Wells et al. 1998) and $£ 200$ million/year in the UK (Hillerton, 1998). Clearly, better diagnosis for mastitis could enable better management of mastitis, leading to possible reductions in these losses. The ideal solution would be a sensor that directly measures milk SCC levels automatically on-line. Currently, farmers have access to indirect estimates of SCC such as in-line conductivity but not to automated on-line sensors that directly measure SCC levels of individual cows. Attempts to automate or standardize the CMT test include the use of rotary viscometers (Nageswararao \& Calbert, 1969; Nichols \& Phillips, 1972) falling ball viscometers (Kiermeier \& Keis, 1964; Carre, 1970) a rolling ball viscometer (Whittlestone \& Allen, 1966; Whittlestone et al. 1970a) or some measurement based on the flow of CMT gel through holes or tubes of various diameters such as the Wisconsin Mastitis Test (Thompson \& Postle, 1964) or Brabant Mastitis Reaction (Jaartsveld, 1962; Bottazzi, 1963). None of these systems were developed for on-line use, probably because of the limited on-farm technology available at the time. The gel has been described as thixotropic (Whittlestone \& Fell, 1965; Whittlestone et al. $1970 b)$, that is, the gel breaks down under shear force but it reforms with the removal of the force. However, neither paper included any data to justify this description. A subset of thixotropic behaviour is rheodestruction, whereby the fluid is irreversibly broken down by the shear stress (Milne, 1976). Milne described the CMT reaction as rheodestructive, having observed breakdown in the CMT gel if excessive vigour was used to mix the milk and reagent. Whittlestone et al. (1970b) described the CMT reaction as non-homogeneous but gave no supporting evidence. 
The purpose of this paper is to review and demonstrate some of the fundamental chemical and rheological aspects of gel formation so that a reliable automated on-line SCC indicator might be developed.

\section{Materials and Methods}

\section{Staining of CMT gel}

A visual staining technique was used to monitor the extent of the gel formation. Milk with high SCC (>5 million cells $/ \mathrm{ml}$ ) was mixed 1:5 with crystal violet stain $(0.4 \mathrm{~g} / \mathrm{l}$ crystal violet in distilled water, Chroma Gesellschaft $\mathrm{GmbH}$, Münster, Germany). This mixture was then combined 1:1 with detergent solution (sodium dodecylsulphate, $0 \cdot 1 \mathrm{~g} / \mathrm{ml}$, in distilled water, SERVA Electrophoresis $\mathrm{GmbH}$, Heidelberg, Germany). Then, $50 \mu \mathrm{l}$ of the final mixture was placed on a microscope slide and covered with a cover slip. Photographs were taken at $100 \times$ magnification.

\section{Visco-elastic properties}

To investigate the visco-elastic properties of the gel, $50 \mathrm{ml}$ of detergent solution and $50 \mathrm{ml}$ of milk with high SCC (>5 million cells $/ \mathrm{ml}$ ) was placed in a plastic 100-ml container. A glass-stirring rod was rotated at approximately $100 \mathrm{rpm}$ in the fluid. A photograph was obtained after approximately $7 \mathrm{~s}$ of rotation.

\section{Rheological properties}

To investigate the time-dependent mechanical properties of the gel, milk samples $(300 \mathrm{ml})$ with various SCC $(2,1 \cdot 3$, $1 \cdot 1,0 \cdot 7$, million cells $/ \mathrm{ml}$ and homogenized milk) were placed in a $600-\mathrm{ml}$ beaker together with $300 \mathrm{ml}$ of detergent solution. When the reagent was added, the viscosity was immediately determined with a commercial viscometer (Brookfield LVDV-II digital viscometer with the LV-4 spindle, at 12 rpm, Middleboro, MA 02346, USA). Viscosity data were logged every other second for at least $10 \mathrm{~min}$.

\section{Results and Discussion}

\section{Staining of CMT gel}

Figure 1 shows the random and chaotic distribution of DNA-histone-detergent strands. Even at this low magnification, it is clear that the gel is non-homogeneous and has a distinct strand-like nature. This random, strand-like nature indicates that the gel is formed in a random or chaotic way. It is evident that a 'web' has formed. This web holds the polymers together, a phenomenon which supports the theory that the reaction forms a gel.

When Milne (1976) observed the formation of the CMT gel under a microscope at an unstated magnification, cells were clearly visible in his plates. At low levels of reagent the cell membranes showed alteration. At a concentration

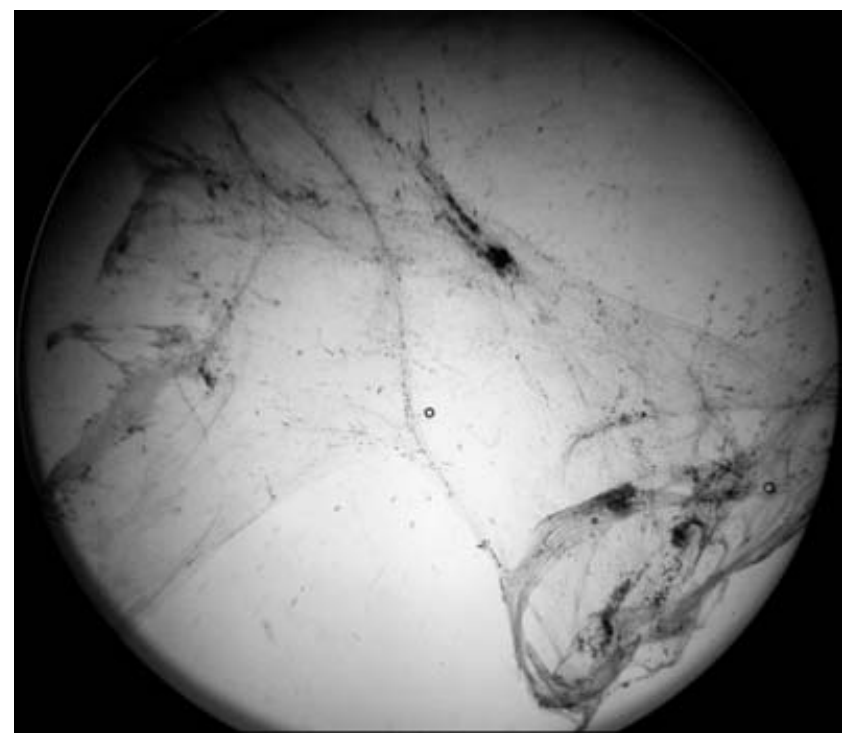

Fig. 1. Stained CMT gel (violet purple) at $\sim 10 \times$ magnification showing non-homogeneous gel formation.

of $4 \%$ and $1: 1$ reagent to milk ratio, he observed that: "nuclear material is apparently re-located to form fibrillar links to adjacent nuclei" and, at high cell counts, "complex knots" are formed between nuclei. Milne's work showed that for dimensions comparable to a cell diameter, the gel was non-homogeneous. Our work confirms that this nonhomogeneity is continued at a bulk level in the CMT gel.

Nageswararao \& Derbyshire (1969) also investigated the CMT gel under $500 \times$ magnification. Their samples were described as an irregularly arranged fibrillar network, a description which matches our results as illustrated in Fig. 1. However, their photographs showed a homogeneous netlike structure. Because their slides were prepared by fixing with formalin or freezing, it is possible that the preparation method caused a more homogeneous sample to form. Furthermore, their magnification was five times higher than ours and it is possible that they photographed an area that was more homogeneous.

\section{Visco-elastic properties}

Visco-elastic fluids have both solid and liquid properties. The visco-elastic properties occur in fluids with long polymer chains that become entangled or crosslinked, such as a plastic polymer melt. This causes the fluid to behave in a non-Newtonian fashion. One simple test for visco-elasticity is the "Weissenberg effect", which occurs when a rod is rotated in a visco-elastic fluid. The fluid climbs up a rotating shaft (Tiu, 1983) instead of forming a vortex because visco-elastic fluids not only transmit shear forces like a Newtonian fluid but also transmit forces through the fluid. This allows the fluid under certain conditions to behave with solid-like properties.

Figure 2 shows that the CMT gel does exhibit the Weissenberg effect and hence is a visco-elastic fluid. The 


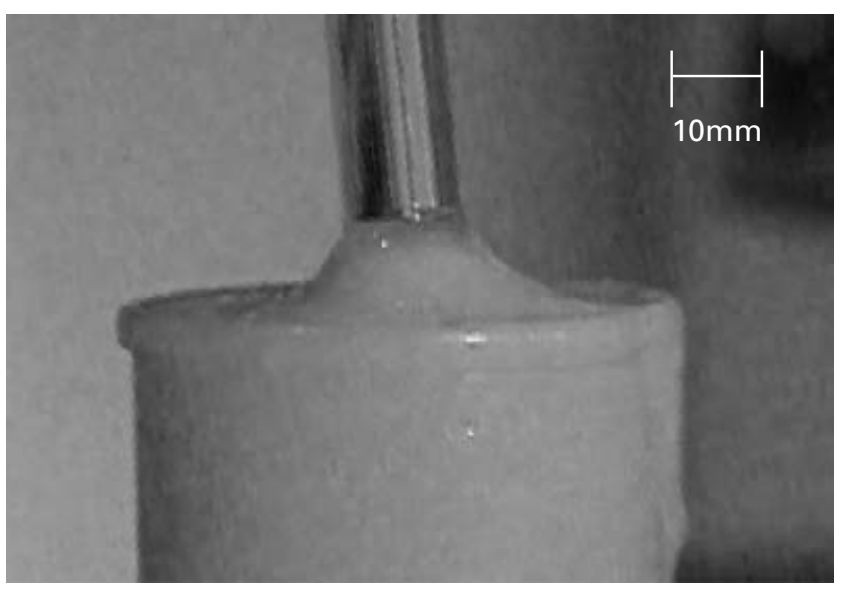

Fig. 2. The Weissenberg effect of the CMT gel climbing a glass stirring rod rotated at approximately $100 \mathrm{rpm}$.

CMT result depends on this visco-elastic property of the gel. For example, a CMT score of 2 is described as follows: "When the mixture is swirled it tends to move in toward the centre, leaving the bottom of the outer edge of the cup exposed. When the motion is stopped, the mixture levels out again, covering the bottom of the cup." A CMT score of 3 occurs when "a distinct gel forms which tends to adhere to the bottom of the paddle and, during swirling, a distinct central peak forms" (Schalm \& Noorlander, 1957). For a fluid to do this, it must have visco-elastic properties because a non visco-elastic fluid could not form a central peak upon swirling but would move out towards the edges, thereby producing a vortex. Our results confirm that the CMT gel is visco-elastic. In the literature there is no recognition or investigation of the visco-elastic nature of the CMT gel.

\section{Rheological properties}

Plots of the change in viscosity of CMT gel formation over time are shown in Fig. 3, for milk samples with various SCC. They show that the slope of the gel formation and the apparent viscosity are directly proportional to the SCC. The time for maximum gel formation ranges from about 1 to $2.5 \mathrm{~min}$, the time falling with decreasing SCC from 2 million to 750000 cells $/ \mathrm{ml}$. Figure 3 confirms results obtained by Nichols (1972) who found that, with a Ferranti type viscometer, the viscosity rose to a maximum and then fell to a lower value after agitation of the sample. Although no numerical data were published, Nichols took the maximum value to represent the viscosity of the gel.

Non-Newtonian fluids do not exhibit a linear relationship between shear stress and shear rate. If a fluid changes its viscosity depending upon what stress has been previously applied, the fluid is described as a time-dependent non-Newtonian fluid. Rheopectic fluids increase their viscosity over time with application of shear forces, while thixotropic fluids have a reversible time-dependent loss of viscosity accompanying the application of shear force

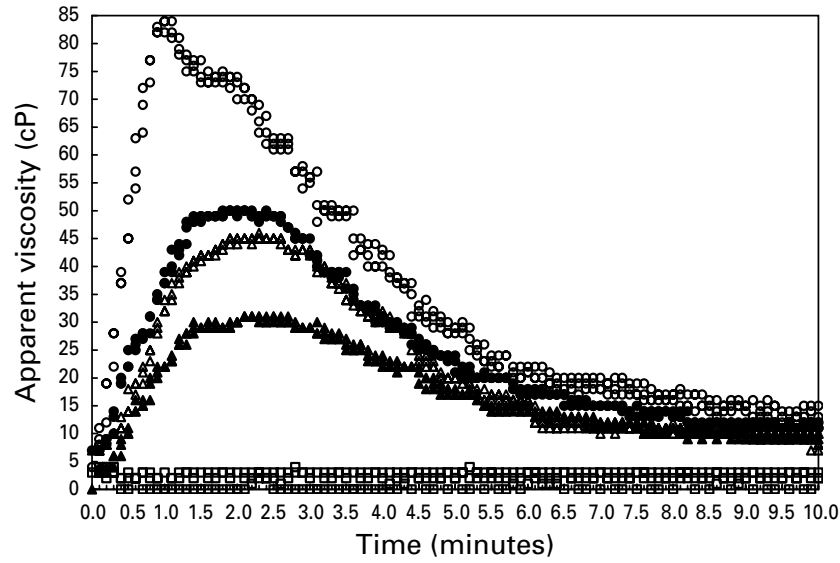

Fig. 3. Change in apparent viscosity of CMT gel over time for various SCC: 2 million cells $/ \mathrm{ml}(\bigcirc) ; 1 \cdot 3$ million cells $(\bullet) ; 1 \cdot 1$ million cells $/ \mathrm{ml}(\triangle) ; 0.7$ million cells $/ \mathrm{ml}(\mathbf{\Delta})$; homogenized and standardized milk $(\square)$.

(Miller, 1960). If the time-dependent loss of viscosity is nonreversible, the fluid is considered to have rheodestructive properties. Figure 3 shows that the CMT gel exhibits rheopectic properties and either thixotropic or rheodestructive properties. Those who have observed many CMT tests will know that continued swirling of the mixture leads to an irreversible observable decrease in the viscosity. Therefore, the time-dependent reduction in the gel's viscosity is rheodestructive rather than thixotropic.

Rheopectic properties. Helenius \& Simons (1975) propose that detergent molecules lyse cells by the absorption of individual reagent molecules into the fat around the cell. This reaction changes the molecular organization of the cell wall which, in turn, alters the cell's permeability and hence the cell's osmotic equilibrium. The cells absorb water and burst allowing leakage of the cellular contents. The property of the cells that form the gel would then take a finite time to react with the detergent, according to Helenius \& Simons. We have a simpler alternative proposition, however. We suggest that the rheopectic nature of the gel is caused by the time taken for the cells to break open, release the DNA and for the DNA-reagent binding to occur.

Fell et al. (1971) studied the effect of mixing time on gel formation using a roll-tube mixer for 20, 40 and $60 \mathrm{~s}$. Increased mixing time resulted in increased viscosity of the CMT gel $(P=0 \cdot 001)$, a result which confirms the rheopectic nature of the CMT gel. However, Fell et al. did not test mixing times longer than $60 \mathrm{~s}$. Because our results show that maximum gel formation does not occur until 60-150 s, improper mixing may have been a significant source of error in the earlier results obtained with the rolling ball viscometer.

The time taken to form a gel and subsequent gel breakdown, once formed, would explain the difficulties that 
Carre (1970) had in trying to measure the viscosity of the CMT gel with the falling ball viscometer. Carre was unable to find a correlation between CMT viscosity and SCC because the CMT viscosity either increased or fell over time. Their result contradicts that of Kiermeier \& Keis (1964) who found a very linear relationship between CMT viscosity and SCC. These conflicting results suggest that Carre might not have used an optimal mixing regime.

Rheodestructive properties. It is likely that the breakdown of the CMT gel may involve three mechanisms: enzymic, chemical and physical shearing:

Enzymic: It is well known that DNase I stops the gel formation. Singh \& Marshall (1966) measured the time taken for the gel to disappear from milk samples scored CMT 3 to 0 by using various concentrations of DNase. Gel reduction occurred in $1 \mathrm{~min}$ for $24 \mathrm{ppm}$, in $1.3 \mathrm{~min}$ for $12 \mathrm{ppm}$, in $5 \mathrm{~min}$ for $2.4 \mathrm{ppm}$ and, for $0 \mathrm{ppm}$, the gel was reduced to a "trace" score in $5 \mathrm{~min}$. It is known that DNase I comes from bacterial production and the mitochondria in somatic cells. A CMT score of 3 has a mean SCC of $9 \cdot 1$ million cells $/ \mathrm{ml}$ with $58 \%$ of samples having counts above 4 million cells $/ \mathrm{ml}$ and $95 \%$ above 1 million cells/ml (Smith \& Schultze, 1966). Mitochondria make up a fifth of cell volume. Therefore, if the mitochondria were completely made up of DNase I, a CMT score of 3 would release $119 \mathrm{ppm}$ of DNase I. Clearly DNase I would only make up a very small part of the mitochondria but we have been unable to deduce an exact figure. Although we have been unable to conclude whether DNase I is an important factor in gel breakdown, we strongly suspect this to be the case.

Chemical: Sodium dodecyl sulpate (SDS) is known as strong protein denaturing detergent. It is this property that allows SDS to sort proteins by size. SDS will disassociate the histone from DNA and the speed at which this occurs is strongly dependent on $\mathrm{pH}$. At $\mathrm{pH} 6 \cdot 2-6 \cdot 3$, histones are removed over a $2-3-\mathrm{h}$ period. However, at $\mathrm{pH} 7 \cdot 0$ there is negligible disassociation even after $96 \mathrm{~h}$ (Dounce et al. 1957). Because milk has a pH of 6.4-8 (Luck \& Smith, 1975), we might expect some denaturing to occur over a 10-min period. The breakdown of the gel having a nonforce dependent variable is further supported by Carre (1970). He found that once maximum gel had formed, the gel naturally broke down over 10-20 min without any applied stress.

Physical shearing: Milne \& Smyth (1976) state that very gentle shear forces cause a significant decrease in viscosity. Whittlestone et al. (1970b) proposed, without detailed explanation, that agitation causes a breakage of the DNA molecule, thereby causing a decrease in viscosity. Physical shearing could be caused by the shear rate or shear stress. The viscosity of solutions containing uncoiled DNA decreased between a shear rate of 40 and 200/s (Robins, 1964). The viscosity of a DNA solution measured by Eisenberg (1957) started to decrease at a shear rate of $4-8 / \mathrm{s}$. This

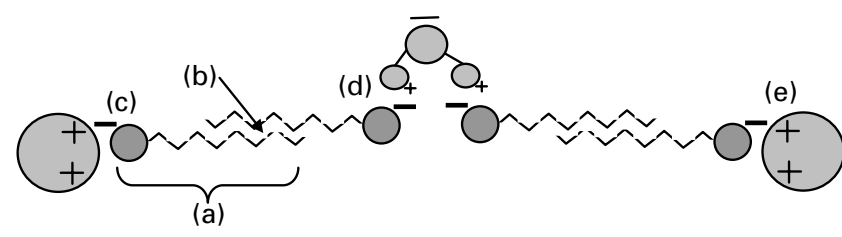

Fig. 4. Gel formation proposed by Christ (1962). The detergent molecules' (a), tails bind to other hydrophobic detergent molecules' tails by Van der Waals forces (b). The negatively charged detergent heads (c), bind to both the positive charge on the water molecules (d), and bind ionicly to the positively charged proteins(e).

shear rate was very dependent on the salinity of the solution which was less than that of milk. The maximum shear rate for the experimental result in Fig. 3 was $2 \cdot 5 / \mathrm{s}$. Therefore, it is plausible that a shear rate of $2 \cdot 5 / \mathrm{s}$ could cause destruction of CMT gel by breaking up the DNA. Hermans \& Hermans (1958) found the viscosity of DNA solutions to be permanently reduced at a shear stress of less than $1 \mathrm{dyne} / \mathrm{cm}^{2}$. The shear stress for our experiment (Fig. 3) was calculated to be 15 dynes $/ \mathrm{cm}^{2}$. Therefore, it is highly probable that the rheodestructive nature of the gel is caused by mechanical break-up of the DNA by shear stress, and possibility shear rate. This hypothesis is further supported by Singh \& Marshall (1966), who found that for a reduction in the CMT gel to occur, they had to swirl the mixture irrespective of the DNase level.

\section{Theory of gel formation}

The result described above leads to a new theory of gel formation. Christ (1962) proposed a gel formation theory illustrated in Fig. 4. He proposed that the CMT gel was formed by an ionic bond between the positive milk proteins, not in the DNA, and the negative detergent. The hydrophobic detergent tail then bonds to other detergent tails via van der Waals forces. The now-exposed negatively charged detergent head then binds to a water molecule. This water molecule then binds to other negatively charged detergent heads, and the detergent tail then binds to other detergent tails whose heads bind to other proteins. According to Christ, this process multiplies and is propagated to form a gel. However, Christ's theory cannot account for the structural rigidity needed for the viscoelastic properties demonstrated by Schalm \& Noorlander (1957) and by the Weissenberg effect in Fig. 2. This is because the binding of the detergent to water molecules would allow fluid movement which would massively reduce, if not destroy, any structural rigidity and the proteins are also free to float in solution.

We propose a different theory of gel formation. It is common knowledge that detergents lyse somatic cells. It is also well accepted that DNA is wrapped around proteins called histones (Garrett \& Grisham, 1999) before being packed into the chromosome complex. We suggest that, once the DNA has been exposed, the negatively 


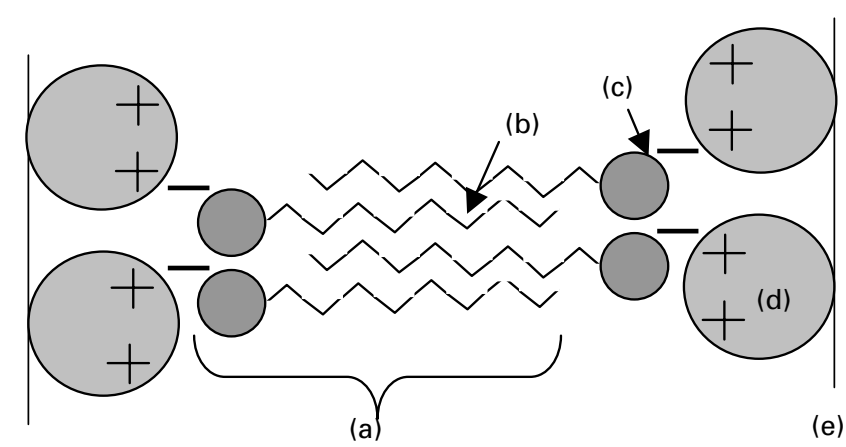

Fig. 5. Schematic diagram of gel formation theory. The detergent molecules' (a), tails bind to other hydrophobic detergent molecules' tails by Van der Waals forces (b). The negatively charged detergent heads (c), ionicly bind to the positively charged protein, probably histones, (d). The proteins are held together by DNA strands (e).

charged detergent molecules form ionic bonds to the positively charged histones. The exposed hydrophilic tail of the detergent molecule then binds to other hydrophobic detergent tails. The now-bound detergents bind their heads to the same or other histones. More detergent molecules bind their hydrophobic tails into the now-forming gel and their negative heads to other histones, thus building up a lattice of detergent, histone and DNA complexes (Fig. 5). The immense length of DNA available, with at least $1 \mathrm{~m}$ per bovine cell, allows many binding sites for the detergent to interact with the histones. This would lead to a chaotic system where detergent molecules bind randomly crosslinking multiple histones. Thus getting the strand-like, but random, gel as shown in Fig. 1. Our theory is supported by the published scientific literature which shows that:

1. DNase inhibits or decreases gel formation (Carrol \& Schalm, 1962; Singh \& Marshall, 1966; Richter et al. 1968; Nageswararao \& Derbyshire, 1969). DNase would break the DNA, allowing the detergent and histones to freely move in solution, thus massively reducing the gel viscosity.

2. Proteinases reduce gel formation. Crude proteases at $0 \cdot 1 \% \mathrm{w} / \mathrm{v}$ can reduce a CMT score from 3 to trace, and bacterial proteinases reduced a CMT 3 to trace (Nageswararao \& Derbyshire, 1969). These workers also found that trypsin and papain at $0.2 \% \mathrm{w} / \mathrm{v}$ combined with $0 \cdot 2 \%$ EDTA reduced gel formation. However, the milk viscosity was increased in this experiment even before the reagent was added. Results from Carrol \& Schalm (1962) showing that trypsin did not reduce the CMT score are more likely to be accurate. The crude proteinases that reduced the CMT gel would digest and alter the histones. The altered tertiary structure of the histones would prevent or modify the ability for the detergent to bind to the histone, thus reducing gel formation.
3. Rise in $\mathrm{pH}$ leads to a more viscous gel (Nageswararao \& Derbyshire, 1969). A rising $\mathrm{pH}$ would make the negative detergent head bind more strongly to the protein.

4. Anionic surfactants interact with proteins. Cheeseman (1968) found that SDS interacts with casein molecules and causes dissociation with high molecular weight casein aggregates. This may cause the dissociated protein molecule to become involved in the CMT gel, thus causing an increase in viscosity. Bovine albumin is known to have a high affinity for anionic reagents with at least seven binding sites (Kragh-Hansen et al. 2001). Therefore, the addition of bovine albumin would reduce the number of reagent molecules that were available for the reaction, thus decreasing the gel formation.

\section{Implications for an automatic sensor}

The chemical and rheological properties of the CMT gel discussed above have significant implications for the development of an on-line automated SCC sensor. Some of these aspects are outlined below.

Potential influence of non-homogeneity on sensor design and performance. Since the gel is non-homogeneous, a large enough sample must be measured to obtain an accurate representation of the overall gel viscosity. This minimum volume depends upon the sensor design and measurement technique and, in particular, the type and timing of the sample taken. The strand-like nature of the gel makes it likely that strands will become entangled on any fittings that protrude into the flow stream, thereby introducing errors in measurement, cleaning problems and sample carryover. Because the size of the container may affect the length of strand possible, the dimensions of any sensor system should be large enough to allow maximum gel formation but small enough so that a gel can form effectively. Repeatability of gel measurement may be reduced because the gel forms randomly. Therefore, a system that repeatably mixes the milk and gel will be essential.

Visco-elastic considerations. The visco-elastic fluid properties of the gel add complexities to the dynamic situations that will arise in any on-line automated SCC sensor. Viscoelastic fluids have a solid-like nature in that they resist change. This may take the form of a yield stress value where a minimum shear stress is reached before there is movement. Although this paper has not focused on measuring gel yield stress values, any sensor measuring the fluid must account for the gel exhibiting yield stress behaviour. If not, viscosity could not be measured because the fluid would appear as a solid.

The visco-elastic gel will transmit both shear and normal direction forces. This is important as these transmitted 
forces may cause rheodestructive breakdown of the gel. Therefore, care must be taken in any sensor design to minimize the transmission of shear and normal stress in the gel and to ensure the gel will flow through the instrument. The apparent viscosity is related to shear rate. Many visco-elastic fluids exhibit a shear thinning effect. This occurs when the rate of shear increases or reaches a particular point at which the apparent viscosity decreases, sometimes rapidly. Therefore, the viscosity measurement has to take place with a rate of shear less than the rate needed to cause shear thinning. Any gel formed from milk with a low SCC will show little sign of visco-elasticity. As SCC level increases, however, so will the visco-elastic nature of the gel. Therefore, a reliable sensor would have to cope with measurements of the viscosity of both a nonNewtonian fluid and a visco-elastic fluid.

Rheopectic and Rheodestructive considerations. The viscosity of gel is both time and shear rate dependent. To measure SCC accurately, therefore, both the time of viscosity measurement and the shear rate need to be known or held constant. The shear rate that the instrument exerts on the gel must be selected with knowledge of the rheopectic and rheodestructive properties of the CMT gel. The time of measurement must also be selected to give maximum resolution. The rheopectic nature of the gel implies that, for maximum gel formation and hence the possibility of maximum resolution, a minimum time is needed to allow the gel to form fully. However, if the time lapse is too long before the viscosity is measured, the gel viscosity may start to decrease and measurement resolution will be lost. The rheodestructive properties imply that any measurement must not apply high shear rates nor stress forces, otherwise the gel will break down too quickly and the measured viscosity values will decrease and may cause a significant loss of resolution.

Detergent effects. The detergents discussed in the literature all belong to a group called anionic surfactants and all have long polar tails. These types of detergents are known to form micelles in watery solutions, as the hydrophobic tails try to minimize water contact. The detergent is in solution as a monomer, micelles or a crystalline suspension. According to detergent theory, only the monomers interact with the cells so that the rate at which the cells are lysed is dependent on the number of monomers in solution. How much reagent is in each state depends on reagent type, concentration, solution temperature and other ions in solution; therefore these variables will all affect the time for the gel to form. The crystalline suspension in the solid is technically known as lysotropic mesomorphism. This is a suspension of the detergent where the detergent has formed liquid crystals in the water solution. These crystals are insoluble since the polar groups are on the outside of the crystals. For example, a common detergent called sodium dodecyl sulphate (SDS) enters crystalline suspension below $10-23{ }^{\circ} \mathrm{C}$ depending on the impurities in solution (Helenius \& Simons, 1975). It is unlikely that the reagent in crystalline suspension will be able to form a CMT reaction since there will be very few monomers in solution.

\section{Conclusions}

The CMT gel is a detergent/DNA/histone complex which is extremely difficult to control and to quantify because it is:

Non-homogeneous - it has a distinct, strand-like nature which indicates that the gel is formed in a random or chaotic way;

Visco-elastic - it has both solid and liquid properties which cause it to behave in a non-Newtonian fashion, that is, forces can be transmitted through the gel;

Rheopectic - the initial viscosity of the gel increases to some maximum level that depends on the elapsed time and the applied shear force as well as SCC;

Rheodestructive-after reaching a maximum level, the subsequent fall in viscosity is non-reversible. The extent and rate of this fall depend on variables such as the elapsed time and the applied shear force.

Clarification of the fundamental biochemistry of CMT gel formation has been made possible by recent advances in biochemical techniques.

The CMT gel has the potential to be used as the basis of a reliable on-line sensor for estimating the SCC of milk from individual cows or quarters or from the bulk milk tank provided that the key variables are clearly understood and carefully controlled.

\section{References}

Bottazzi V 1963 [Contribution To The Method of Recognition of mastitic milk]. IL Latte 37 755-759

Carre X 1970 [Effect of leucocyte of the viscosity of milk in the sodium lauryl sulphate test for mastitis]. Thesis, Ecole Nationale Veterinaire Lyon

Carroll EJ \& Schalm OW 1962 Effect of Deoxyribonuclease on the California Mastitis Test for Mastitis. Journal of Dairy Science $\mathbf{4 5}$ 1094-1097

Cheeseman GC 1968 A preliminary study by gel filtration and ultra centrifugation of the interaction of bovine milk caseins with detergents. Journal of Dairy Research 35 439-450

Christ W 1962 [The reactive capacity of proteins with synthetic detergents as a base for the understanding of the California mastitis test]. Deutsche Tierarztliche Wochenschrift 69 108-110

Dounce AL \& Monty KJ 1955 Factors influencing the ability of isolated cell nuclei to form gels in dilute alkali. Journal of Biophysical and Biochemical Cytology 1 155-160

Dounce AL, O'Connell MP \& Monty KJ 1957 Action of mitochondrial DNase I in destroying the capacity of isolated gel nuclei to form gels. The Journal of Biophysical and Biochemical Cytology 3 649-661

Eisenber H 1957 Viscosity of dilute solutions of preparations of deoxyribonucleic acid at low and medium rates of shear. Journal of Polymer Science 26 257-271

Fell I, Whittlestone W \& De Langen H 1971 Factors affecting the viscometric method for estimating the somatic cell count of cow's milk. Journal of Milk Food Technology 34 82-84 
Garrett RH \& Grisham CM 1995 Biochemistry. 2nd Edition Orlando, FL: Saundars College Publishing, Harcourt Brace College Publishers

Helenius A \& Simons K 1975 Solubilization of membranes by detergents. Biochimica et Biophysica Acta 415 29-79

Hermans J \& Hermans JJ 1958 The non-Newtonian behaviour of deoxyribonucleic acid solutions. Physical Chemistry 61 324-332

Hillerton EJ 1998 Mastitis treatment - a welfare issue. Proceedings. British Mastitis Conference, Stoneleigh, UK

Jaartsveld FHJ 1962 Contribution to diagnosis of mastitis in cattle in connection with mastitis control. Netherlands Milk and Dairy Journal 16 260-264

Kragh-Hansen U, Hellec F, De Foresta B, Le Maire M \& Moller JV 2001 Detergents as probes of hydrophobic binding cavities in serum albumin and other water-soluble proteins. Biophysical Journal 802898 2911

Kiermeier F \& Keis K 1964 [Semi-quantitative modification of the Schalm test]. Milchwissenschaft 19 65-69

Luck H \& Smith A 1975 Relationship between constituent concentrations and the $\mathrm{pH}$ value of mammary gland secretions. South African Journal of Dairy Technology 7 27-30

Miller JT 1960 The Instrument Manual 3rd Edition. London: United Trade Press Ltd

Milne J \& De Langen H 1977 Observations on the California Mastitis Test (CMT) reaction. 1. The roles of deoxyribonucleic acid (DNA) and milk proteins in the reaction. New Zealand Journal of Dairy Science and Technology 12 44-47

Milne J \& Smyth R 1976 Rapid determination of somatic cells in milk. New Zealand Journal of Dairy Science and Technology 11 21-23

Nageswarao G \& Calbert HE 1969 A comparison of screening tests to detect abnormal milk. Journal of Milk Food Technology 32 365-368

Nageswarao G \& Derbyshire JB 1969 Studies on the mechanism of gel formation in the California mastitis test reaction. Journal of Dairy Research 36 359-370

Nichols MG \& Phillips DSM 1972 A rotary viscometer for leucocyte-count determinations in milk. Australian Journal of Dairy Technology 27 134-136
Ott SL, Seitzinger AH \& Wells SJ 1998 Key health issues for dairy cattlenew and old. Journal of Dairy Science 81 3029-3035

Richter RL, Randolph HE \& Rundick AW 1968 Factors affecting the Wisconsin mastitis test. Journal of Milk Food Technology 31 289-292

Robins AB 1964 Non-Newtonian behaviour of dilute DNA solutions. Transactions of the Faraday Society 60 1344-1351

Schalm OW \& Noorlander DO 1957 Experiments and observations leading to development of the California mastitis test. Journal of the American Veterinary Medical Association 130 199-204

Singh B \& Marshall RT 1966 Bacterial deoxyribonuclease production and its possible influence on mastitis detection. Journal of Dairy Science 49 822-824

Smith JW \& Schultze WD 1966 The cellular content of cow milk. 1. An evaluation of the California mastitis test as a method of estimating the number of cells in milk. Journal of Milk Food Technology 29 84-87

Thompson DI \& Postle DS 1964 The Wisconsin mastitis test - An indirect estimation of leucocytes in milk. Journal of Milk Food Technology 27 $271-275$

Tiu C \& Boger DV 1983 Rheology and Non-Newtonian Fluid Mechanics. Melbourne, Australia: Department of Chemical Engineering, Monash University

Wells SJ, Ott SL \& Hillberg Seitzinger A 1998 Key health issues for dairy cattle - new and old. Journal of Dairy Science 81 3029-3035

Whiteside WH 1939 Observations on a new test for the presence of mastitis in milk. Canadian Public Health Journal 3044

Whittlestone W \& Allen D 1966 An automatic viscometer for the measurement of the California mastitis reaction. Australian Journal of Dairy Technology 21 138-139

Whittlestone W \& Fell I 1965 A viscometer for routine mastitis test. Proceedings of 36th Annual Conference of New Zealand Dairy Science Association pp. 21-22

Whittlestone W, De Langen H \& Cate L 1970 A simple semi-automatic viscometer for the estimation of somatic cells in milk. Milchwissenschaft 27 84-86

Whittlestone W, Fell I \& De Langen H 1970 A viscometric method for the estimation for milk cell count. Journal of Milk Food Technology 33 $351-354$ 